\title{
O PAPEL DO TRANSPORTE RODOVIÁRIO DE CARGA EM UBERLÂNDIA, EPICENTRO LOGÍSTICO DO SETOR ATACADISTA-DISTRIBUIDOR
}

\author{
The role of road freight in Uberlândia (Brazil), \\ logistics epicenter of wholesaler-distributor sector
}

Daniel Monteiro Huertas

Universidade Federal de São Paulo, Osasco, São Paulo, Brasil dmhuertas@unifesp.br

Artigo recebido em 06/05/2014 e aceito para publicação em 18/07/2014

RESUMO: Em análise estruturada a partir da teoria do espaço geográfico e dos circuitos da economia urbana, este artigo pretende demonstrar as peculiaridades e dinâmicas territoriais que corroboram a inserção do ponto nodal de Uberlândia (MG) como uma das centralidades da rede geográfica do transporte rodoviário de carga, cuja configuração territorial é composta por linhas e nodais que em seu conjunto expressam a organização e estruturação desta atividade na formação socioespacial brasileira. Além disso, evidenciam um processo de seletividade espacial que privilegiou certos pontos e áreas em detrimento de outros, demarcado pela concentração e atuação de seus agentes. A pesquisa conclui que a inserção de Uberlândia na rede geográfica proposta se dá por causa da estreita relação entre os agentes do transporte rodoviário de carga e do setor atacadista-distribuidor.

Palavras-chave: transporte rodoviário de carga, circulação, nodal e seletividade espacial.

ABSTRACT: In structured analysis from the theory of geographical space and the circuits of urban economy, this article aims to demonstrate the peculiarities and territorial dynamics that confirmed the insertion of the Uberlândia (MG) nodal point like one of centralities of road freight transport geographical network, whose territorial configuration consists of nodals and lines which together express the organization and structuring of this activity in the Brazilian social and spatial formation. Furthermore, it show a selective spatial process that privileged certain points and areas in detriment of others, marked by concentration and action of its agents. The research concludes that the inclusion of Uberlândia in the geographical proposed network occurs because of the close relationship between the agents of road freight and wholesaler-distributor sector.

Keywords: road freight transport, circulation, nodal and spatial selectivity. 


\section{INTRODUÇÃO}

O aprofundamento e a capilaridade da globalização pelo território nacional a partir de meados dos anos 1990 impuseram mudanças profundas no cenário do comércio exterior, das forças produtivas e do padrão de consumo, elementos que, em conjunto, também impactaram o transporte rodoviário de carga, cujas variáveis são capazes de revelar o uso do território no período atual. Nessa perspectiva, a logística, como versão atual da circulação corporativa caracterizada por um conjunto de competências operacionais, materiais e normativas (CASTILLO, 2011), surge de forma arrebatadora e acarreta mudanças estruturais e conjunturais em toda a instância produtiva e no seu enlace com a circulação.

A promulgação da lei $\mathrm{n}^{0} 11.442$, de 5 de janeiro de 2007, instituiu um novo quadro normativo e enquadrou o transporte rodoviário de carga (TRC) como aquele "realizado em vias públicas, no território nacional, por conta de terceiros e mediante remuneração", cuja atividade econômica "é de natureza comercial, exercida por pessoa física ou jurídica em regime de livre concorrência", segundo os artigos $1^{\circ}$ e $2^{\circ}$ da lei supracitada.

A norma, portanto, distingue o transporte rodoviário de carga da figura do carga própria (agente que não realiza o transporte com natureza comercial) e também procura discriminar e disciplinar os seus agentes (empresas de transporte rodoviário de carga/ ETC e transportadores autônomos de carga/TAC, agregados e independentes) e atividades correlatas mediante coordenação e fiscalização da Agência Nacional de Transportes Terrestres (ANTT). Trata-se de um universo de 128.700 empresas transportadoras, 689.953 motoristas autônomos e 1.911 .172 veículos espalhados por todos os cantos do país, segundo dados da ANTT (15.mai.2013).

Em análise estruturada a partir da teoria do espaço geográfico, o uso do território pode ser evidenciado por um processo de seletividade espacial que privilegiou certos pontos e áreas em detrimento de outros. Como o transporte também pode ser considerado um dos fatores locacionais por conta das possibilidades que oferece para a redução de custos (THOMSON, 1976), os agentes dos circuitos espaciais de produção
(SANTOS, 1988) buscam atuar em sintonia com os agentes do TRC.

As solidariedades organizacionais geradas estimulam e facilitam a localização dos agentes em pontos privilegiados do território, geralmente nodais situados em tramos estratégicos da rede rodoviária e da rede urbana. Afinal, como já nos disse Milton Santos (2004) em sua análise do imperativo da fluidez, não basta produzir; é indispensável pôr a produção em movimento.

Levando-se em consideração que o TRC cria uma topologia própria, cuja configuração territorial é composta por linhas e nodais que em seu conjunto modelam uma rede geográfica capaz de expressar a sua organização e estruturação na formação socioespacial brasileira (HUERTAS, 2013), este artigo pretende demonstrar as peculiaridades e dinâmicas territoriais que corroboram a inserção do ponto nodal de Uberlândia (MG) como uma das centralidades da rede em questão.

Trata-se de um nodal secundário monofuncional, diretamente atrelado à logística do comércio atacadista-distribuidor (como será visto mais adiante), que em seu conjunto registra seis matrizes de empresas transportadoras e 70 filiais na principal cidade do Triângulo Mineiro, segundo a pesquisa realizada. Como eixos rodoviários centrais foram consideradas as BRs 050 (até Brasília, ao norte, e à divisa MG/SP, ao sul), 365 (até Montes Claros/MG, a leste, e São Simão/GO, a oeste) e 452 (Uberlândia-Araxá).

\section{NODAIS COMO MÁXIMA EXPRESSÃO DA SELETIVIDADE ESPACIAL}

O ponto inicial analítico proposto, em termos de circulação, é a configuração de uma rede geográfica do transporte rodoviário de carga reveladora do uso do território. Roberto Lobato Corrêa (1997, p.306) demonstra como as redes geográficas são construções sociais "historicamente contextualizadas, constituindo-se em parte integrante do longo e cada vez mais complexo processo de organização espacial", e locus da efetivação das interações espaciais "a partir dos atributos das localizações e das possibilidades reais de se articularem entre si”.

Organizamos o estudo da rede geográfica em questão para o território brasileiro levando em consi- 
deração funcionalidades, hierarquias e polarizações, atributos que em seu conjunto mais amplo denotam tanto a dissociação quanto a conectividade geográfica dos lugares e a seletividade espacial. Acreditamos, assim, que este caminho metodológico proporcione uma leitura bastante interessante no que diz respeito ao uso do território, evidenciando com mais força a hierarquia dos lugares gerada pela circulação diferenciada do excedente (ARROYO, 2005).

Os nodais ajudam a explicar a rede geográfica e são tidos, portanto, como a expressão máxima da seletividade espacial do transporte rodoviário de carga pela densidade de fixos e pela frequência, qualidade e intensidade dos fluxos. Do ponto de vista operacional, apenas nos nodais registra-se a possibilidade de implementar uma distribuição territorial completa das mercadorias em fluxos T1 (escala nacional-T1/A, macrorregional-T1/B e mesorregional-T1/C) e T2 (escala microrregional-T2/D, intraurbana metropolitana-T2/E e intraurbana intermediária-T2/F), cujos movimentos demarcam a escala de atuação de empresas transportadoras e motoristas autônomos (HUERTAS, 2013).

Além disso, são os principais pontos de origem e destino de todo o movimento de carga lotação (ou carga fechada, com carregamento num único ponto e entrega num único ponto) empreendido no país, embora não haja estatísticas que possam comprovar este fenômeno.

Logo de imediato é importante salientar algumas considerações gerais a respeito dos nodais. Em todos os casos ocorre uma espécie de "nexo territorial", consubstanciado pela conjugação entre a capacidade dos agentes instalados em condicionar arranjos territoriais em todas as escalas (fluxos T1 e T2), a formação do valor do frete e as amplas condições de fluidez territorial, o que significa situação locacional em trechos privilegiados da rede rodoviária nacional e acesso facilitado a portos, ferrovias, hidrovias e aeroportos. Corresponde, portanto, às interações espaciais que reforçam a interconectividade entre os agentes do transporte rodoviário de carga e destes com os agentes dos circuitos espaciais de produção.

Esta condição única no território nacional, portadora de verticalidades que criam e recriam solidariedades organizacionais, revela a estrutura e orga- nização socioeconômica e política superior dos nodais em relação ao TRC. “...as metrópoles econômicas nacionais usufruem de posição estratégica na moderna rede de transporte. Isso lhes assegura relações mais fáceis com o resto do território, aumentando assim sua capacidade de competição" (SANTOS, 2008, p.309).

As características acima denotam a localização dos fixos mais estratégicos em termos de expedição, transferência e consolidação de carga e capacidade de armazenagem, além da presença de pessoal mais qualificado para o desenvolvimento das tarefas administrativas e operacionais que envolvem o TRC. Segundo estudo do Geipot citado por Silva Junior (2004), 1/3 do total da frota de caminhões do país opera em percursos rodoviários (fluxos T1 e T2/D), viagens de média e longa distância com custos de transferência representativos por causa dos fixos. Soma-se a isso o fato de que nas operações de coleta e entrega (fluxos T2/E e T2/F), cujo volume também está bastante concentrado nos nodais, os custos fixos dos veículos perfazem mais de $60 \%$ do total dos custos operacionais, segundo Giúdice (2012).

Entende-se assim que os nodais concentram boa parte dos custos totais do TRC, elemento fundamental para o planejamento estratégico do circuito superior. No plano político, concentram grande parte das instituições responsáveis pela representação de suas categorias, com capacidade de debater e direcionar os assuntos normativos correlatos à atividade, com forte influência na regulamentação do setor. "Em regra geral, os atores que possuem os nós detêm o controle dos dispositivos: é nos polos que se efetua o tratamento estatístico dos objetos, garantia da qualidade da prestação global, que se organiza a cadeia de entrega com suas subcontratações hierárquicas" (SAVY, 1993, p.216; tradução livre).

De modo geral, observa-se que todas as características supracitadas são típicas de cidades com maiores níveis de especialização e diversificação econômica, em hierarquias superiores na rede urbana brasileira, cuja concentração de variáveis diretamente relacionadas ao TRC proporciona uma sinergia territorial entre os agentes e acaba reforçando o poder de polarização e centralidade das aglomerações urbanas onde se localizam - geralmente no entorno de grandes cidades, nós de circulação e pontos de convergência 
das vias de comunicação com interpenetração de circulação geral e local (CLOZIER, 1963).

No processo de urbanização, há [...] uma tendência crescente à diferenciação e à especialização, acompanhada de uma maior divisão interurbana do trabalho, e atrelada diretamente às possibilidades de articulação que a dinâmica da circulação promove (ARROYO, 2006, p.76).

De certa forma o nodal está vinculado a uma economia complexa, "caracterizada, e viabilizada, por uma complexa divisão territorial do trabalho", e associado à rede urbana, "cujos centros estão fortemente integrados entre si" (CÔRREA, 2006, p.306). Mas os nodais também revelam situações intermediárias, que ajudam a compreender com mais profundidade a correlação de forças entre os agentes do transporte rodoviário de carga e os níveis inferiores da rede urbana brasileira.

Esses sistemas de tessituras, de nós e de redes organizadas hierarquicamente permitem assegurar o controle sobre aquilo que ser distribuido, alocado elou possuido. Permitem ainda impor e manter uma ou várias ordens. Enfim, permitem realizar a integração e a coesão dos territórios. Esses sistemas constituem o invólucro no qual se originam as relações de poder (RAFFESTIN, 1993, p.151).

Além disso, se a circulação diferenciada do excedente cria uma hierarquia entre os lugares (ARROYO, 2005), os nodais podem ser analisados, também, pelas grandes possibilidades que oferecem para reter boa parte deste excedente, porque "sem a circulação de bens não há circulação do excedente" (SANTOS, 2003, p.144).

São nos nodais que se materializam no território as maiores possibilidades das metamorfoses M-D e D-M explicadas por Karl Marx no processo de circulação do capital. Neste, a renovação do processo produtivo depende da duração do tempo de circulação, decomposto em duas fases opostas M-D e D-M, "o tempo que precisa para se transformar de mercadoria em dinheiro e o que precisa para se converter de dinheiro em mercadoria" (MARX, 2011, p.141). Este fenômeno intensifica o que ele chamou de "processo adicional da produção da indústria de transportes", visível na densidade dos atributos geográficos que constituem os nodais, como será visto mais adiante.

Além disso, são nos nodais que a aplicação da lei geral da produção de mercadorias, que também "se aplica à indústria de transportes como a qualquer outra" (MARX, 2011, p.167), adquire a sua condição plena, pois a concentração de agentes da circulação nesses nexos territoriais favorece a diminuição dos custos de transporte.

Ademais, valendo-se ainda da teoria marxista, são nos nodais que residem as maiores possibilidades de balanceamento entre o tempo de compra e de venda - cuja soma define o tempo de circulação do capital, uma das frações do ciclo de circulação do capital como um todo -, pois "o afastamento do mercado prolonga o tempo em que o capital fica prisioneiro da forma de capital-mercadoria, retarda diretamente o retorno do dinheiro, por conseguinte a transformação do capital-dinheiro em capital-produtivo" (MARX, 2011, p.290).

O autor explica que a repartição do retorno do dinheiro "por maior número de períodos sucessivos encurta o tempo global de circulação e, por conseguinte, a rotação" (MARX, 2011, p.287), condição possível, para o caso específico da formação socioespacial brasileira, pelo entrelaçamento territorial proporcionado pelos nodais, que amarram os principais mercados produtores e consumidores de um país com dimensões continentais e desequilíbrios regionais.

Nos nodais observa-se um melhor desenvolvimento dos meios de transporte, fato que "aumenta a velocidade do movimento no espaço e assim reduz-se no tempo a distância geográfica" (MARX, 2011, p.286). Esta redução absoluta do tempo de viagem das mercadorias, embora permaneça a diferença relativa, só é possível pela maior frequência com que funcionam os agentes da circulação nos nodais, além da amplitude de suas escalas de atuação no território nacional.

Na divisão territorial do trabalho do período atual, os nodais do transporte rodoviário de carga, locus de alta produtividade espacial ou subsistemas 
logísticos que facilitam a fluidez e hierarquizam o território pelos seus requisitos técnico-organizacionais (SANTOS, 2004), proporcionam um movimento convergente de articulação do todo nacional, embora o espaço se torne "mais articulado às relações funcionais, e mais desarticulado quanto ao comando local das ações que nele se exercem" (SANTOS, 2005, p.49). A análise geográfica, portanto, parte do princípio de que o espaço também se impõe por meio das condições que oferece para a circulação.

\section{ATRIBUTOS GEOGRÁFICOS DOS NODAIS QUE REFORÇAM CENTRALIDADES}

Como visto anteriormente, o nodal denota a capacidade de produzir, coletar, armazenar e distribuir das áreas sob sua influência e se torna uma arena territorial privilegiada aos agentes por causa da cadeia de subcontratações, que aí encontra as maiores probabilidades de realização pelo encontro entre oferta e demanda por serviço de transporte. No embate entre arena e área, proposto por Milton Santos (2005), os nodais são arenas que proporcionam o alargamento de atuação territorial dos agentes dos circuitos inferior e superior, ou seja, de suas áreas de operação - que podem ser rotas programadas ou de acordo com a conveniência do cliente.

Como escolher, então, as variáveis, ou melhor, os atributos geográficos constituintes dos nodais do TRC? Ao longo da pesquisa, fruto da observação empírica de nosso objeto de estudo, foi concebido um agrupamento tipológico sob o prisma da correlação do trinômio máquina (veículo) $\leftrightarrow$ agentes da circulação $\leftrightarrow$ fixos (rodovias e suportes). Os elementos escolhidos e discriminados abaixo, com elevado grau de concentração nos nodais, tem como objetivo comprovar territorialmente a densidade e escala de objetos ligados direta ou indiretamente ao TRC, o que de certa forma ajuda a corroborar a hierarquia dos lugares no que diz respeito à circulação:

(1) Veículos: revendas de todas as marcas de caminhão comercializadas no Brasil (Agrale, Ford, Hyundai, International, Iveco, MAN, Mercedes-Benz, Scania, Volvo e Sinotruk); rede de distribuidores dos cinco mais expressivos fabricantes de implementos rodoviários (Randon, Librelato, Facchini, Noma e Guerra) e oficinas Bosch Diesel Center, tidas como especializadas em serviços mecânicos e eletrônicos com soluções de reparo dos sistemas diesel (Common Rail e outros) em equipamentos de última geração.

Também é importante destacar que ao longo dos nodais, mais especificamente nas principais vias e trevos de acesso às cidades que os compõem, registra-se uma miríade de oficinas que prestam inúmeros serviços de manutenção e reparo de caminhões e implementos rodoviários, borracharias e revendas de veículos usados. São estabelecimentos de todos os portes - precários e modernos; pequenos, médios e grandes -, mas constantemente presentes na paisagem. Alguns funcionam 24 horas, sempre aptos a prestar assistência ao caminhoneiro.

Dentre os serviços mais ofertados estão chapeação (funilaria), pintura, lavagem, autoelétrico, recapagem de pneu, retífica e usinagem de motores, substituição de bomba injetora de óleo diesel, troca de lona de freio e reparo de diferencial e caixa de câmbio. Os postos de combustível, além do abastecimento, funcionam como ponto de apoio e oferecem pequenos serviços emergenciais de mecânica, lavagem, calibragem de pneus, sanitários, restaurante e estacionamento para pernoite. Alguns ainda possuem serviços como barbearia, salão de jogos, sala de TV, comércio de artigos para caminhão (adornos, enfeites, lâmpadas, para-choques, adesivos etc) e agenciamento de carga.

(2) Agentes: Empresas transportadoras de carga (ETC) e transportadores autônomos de carga (TAC) cadastrados no Registro Nacional de Transportadores Rodoviários de Carga (RNTRC) da ANTT; motoristas com vínculo empregatício segundo a Relação Anual de Relações Sociais do Ministério do Trabalho e Emprego (Rais/MTE); unidades do Sistema Sest/ Senat, mantido pela contribuição sindical de todos os agentes e gerenciado pela Confederação Nacional dos Transportes (CNT), e organização sindical do empresariado e de autônomos.

(3) Fixos logísticos: cada tipo de fixo surge com características próprias (técnicas e organizacionais) que corresponde a uma tipologia de fluxos (SANTOS, 1988). Desse modo o funcionamento do 
território não pode ser compreendido sem a alocação dos fixos que captam o movimento de boa parte dos fluxos rodoviários que perpassam o território nacional, seja para o mercado interno ou externo. Além disso, são grandes indicadores das forças de dispersão e concentração geradas pelo binômio informação-consumo (SANTOS, 2008), ponto central para a compreensão dos circuitos espaciais e círculos de cooperação do TRC.

Em sua proposição de uma tipologia de nós geográficos, Vanderlei Braga (2013, p.45) coloca como objetivo "discriminar e classificar os sistemas técnicos que envolvem o movimento de mercadorias, sem esquecer as relações políticas, econômicas e sociais que articulam e hierarquizam estes pontos, planejados para serem estrategicamente localizados no território". Para o autor, os nós geográficos podem ser classificados "de acordo com sua função e complexidade, decorrentes de distintas combinações entre objetos técnicos e normas que incorporam" e estão subdivididos em nós de comunicação e de circulação. Estes, por sua vez, incorporam nós de transporte de passageiros, de transporte de cargas simples e logísticos.

Levando-se em consideração os dois últimos, que nos interessam mais de perto, observamos que armazéns simples, centrais (ou centros) de distribuição, plataformas e condomínios logísticos, terminais intermodais (aeroportuários, aquaviários e ferroviários) e centros logísticos e industriais aduaneiros (Clias) estão entre os fixos adotados pelo autor para corroborar o seu ponto de vista. Em nossa análise, focada no TRC, acrescentaremos os pontos de combustível com agenciamento de carga, os recintos alfandegados pela Receita Federal (portos secos e pontos de fronteira), as unidades superiores de triagem dos Correios e os entrepostos da Zona Franca de Manaus (EZFM).

(4) Rede rodoviária: em conjunto com os nodais, as linhas rodoviárias de circulação revelam a rede geográfica do TRC. Como aponta Brandão (2009, p.78-9), "tornar os espaços conexos não é uma tarefa que ocorre com naturalidade", e a ação das forças de integração "geralmente constitui um longo, contraditório, heterogêneo e conflituoso processo em que os espaços regionais circunscritos e capsulares vão sendo enredados a partir daquele(s) espaço(s) em que prevalecem formas superiores de acumulação e reprodução econômica".

É fato que a expansão rodoviária no país é iniciada nos anos 1930 com Getúlio Vargas e incrementada sucessivamente por Juscelino Kubitschek e pela ditadura militar ao longo da segunda metade do século XX. Em outras palavras, o enraizamento das linhas rodoviárias só pode ser compreendido mediante análise do processo histórico da formação socioespacial brasileira, que deve mostrar porque uma via foi aberta; e mais, porque foi aberta para ligar os pontos $\mathrm{A}$ e $\mathrm{B}$, e não $\mathrm{A}$ e $\mathrm{C}$. Geralmente, há um imbricamento de motivações geoeconômicas e geopolíticas; muitas vezes, uma prevalece sobre a outra.

Mas como pensar as linhas de circulação para a proposta deste trabalho e para o período atual? Primeiramente concordamos com a assertiva de Milton Santos (2008, p.313) sobre a rede de transportes nos países subdesenvolvidos, "nem homogênea nem contínua, mas dendrítica", cujas principais rodovias "ligam os grandes centros de produção aos principais centros de consumo". Optamos por um esquema simples, composto por três conjuntos rodoviários:

- Eixos centrais (estruturantes): são as ligações de alta densidade de tráfego e de grande importância geoestratégica, uma malha de linhas de circulação que conecta os nodais superiores do TRC majoritariamente por rodovias federais (BRs). Em termos econômicos confundem-se com as linhas de desejo que servem as principais economias de escala do país.

- Eixos complementares: são ligações de média densidade de tráfego e de caráter mais intrarregional e/ou intraestadual do que inter-regional e/ou interestadual. Compõem as rodovias que atendem os eixos centrais tanto no seio dos nodais quanto na ligação entre linhas de nível superior. Neste caso, aparece um conjunto bastante significante de vias estaduais, sobretudo na Região 
Concentrada.

- Eixos em configuração na Amazônia: incluída no Programa de Aceleração do Crescimento (PAC), a pavimentação em andamento dos trechos Guarantã do Norte/ MT-Santarém/PA da Cuiabá-Santarém (BR163), Altamira-Marabá da Transamazônica (BR-230/PA) e Ribeirão Cascalheira/MTdivisa MT/PA da BR-158 a curto e médio prazos modificará a configuração territorial de extensas áreas entre o sul do Pará e o médio-norte do Mato Grosso, com iminentes impactos socioambientais.

\section{RECORTES ESPACIAIS E TOPOLOGIA DOS NODAIS}

Acreditamos que a busca por uma rede geográfica promovida e desenhada pelo TRC como resultado da divisão territorial do trabalho encontre sentido exatamente na definição de espaços de fluxos reguladores - os nodais em suas manifestações topológicas - interligados por linhas de circulação que abarcam boa parte do território nacional. Admitimos, entretanto, que esta escolha - materializada em uma rede composta por linhas e nodais do TRC - pode incorrer em arbitrariedades comuns a qualquer tipo de recorte espacial estabelecido a partir de quaisquer variáveis (demográficas, econômicas, culturais, políticas etc). Não se trata de uma camisa-de-força, mas de uma sugestão para um melhor entendimento do papel do TRC na organização e estruturação da formação socioespacial brasileira.

Os nodais não deixam de ser aglomerações e a compreensão da divisão territorial do trabalho inclui, necessariamente, a análise funcional e hierárquica do TRC - evidenciando, assim, o uso do território. Milton Santos (2004, p.284; grifo nosso) nos explica que, nas atuais condições, "os arranjos espaciais não se dão apenas através de figuras formadas de pontos contínuos e contíguos". E continua: "Hoje, ao lado dessas manchas, ou por sobre essas manchas, há, também, constelações de pontos descontínuos, mas interligados, que definem um espaço de fluxos reguladores."

O recorte espacial dos nodais, como proposta metodológica, considera a relação entre quantidade e contiguidade de matrizes (sedes das empresas) e seus fixos correlatos (filiais, centros de operação, pontos de apoio, centros de distribuição, agências, centros de envio e franquias) de uma relação de 800 empresas transportadoras levantadas em pesquisa de elaboração própria como o indicador que esclarece os arranjos territoriais do TRC ao longo da formação socioespacial brasileira, relacionando-o com a rede rodoviária nacional e a rede urbana (HUERTAS, 2013). A pesquisa apontou 7.401 fixos em 1.087 cidades de todas as Unidades da Federação, sendo que, respectivamente, $6.936(93,71 \%)$ e $695(63,93 \%)$ estão situados nos nodais, classificados em quatro níveis:

(i) Primário: "polígono paulista", força polarizadora única no território nacional que acolhe 304 matrizes ( $38 \%$ do total), com 1.618 fixos (21,8\%) alocados em 144 cidades (13,2\%), e responsável pela determinação das rotas, prazos de tempo de trânsito de carga e valor do frete de boa parte do país;

(ii) Secundários polifuncionais: aqueles em que os circuitos espaciais de produção industrial são o suporte das atividades geradoras de carga, tornando o seu tecido econômico mais diversificado e complexo;

(iii) Secundários monofuncionais: aqueles cuja tipologia pode estar relacionada à especialização produtiva (circuitos espaciais de produção petrolífera e agropecuária), à situação geográfica (acesso fronteiriço ao Mercosul) ou à logística do comércio atacadista e distribuidor e da produção salineira;

(iv) Terciários (relês regionais): centros responsáveis por fluxos $\mathrm{T} 2 / \mathrm{D}$ (rotas microrregionais) e T2/F (cidades intermediárias).

A configuração de um nodal em cidades que dispõem de pelo menos três fixos e/ou de uma matriz é uma condição restrita ao nodal terciário, o mais baixo da classificação proposta. Os dois níveis superiores, ou nodais primários e secundários, somente ocorrem em cidades com seis ou mais fixos e pelo menos uma matriz, sendo que a sua composição completa, no caso de eixos e polígonos, deve incluir também 
todas as cidades adjacentes aos seus eixos rodoviários estruturantes que contam com pelo menos um fixo.

De certa forma, esta proposta metodológica constrói-se a partir do circuito superior do transporte rodoviário de carga (grandes e médias transportadoras), embora os circuitos superior marginal e inferior (pequenas transportadoras e motoristas autônomos) estejam diretamente atrelados e subordinados, espacialmente falando, aos desígnios técnico-operacionais e informacionais dos agentes hegemônicos.

Cabe ressaltar que em sua teorização sobre o espaço dividido Milton Santos explicita o fato de que a diferença fundamental entre as atividades dos circuitos inferior e superior está ancorada nas diferenças de tecnologia e organização, e destaca que "não são sistemas isolados e impermeáveis entre si, mas, ao contrário, estão em interação permanente" (2008, p.261). O circuito superior marginal gravita entre ambos, revelador de um movimento de transição permanente e igualmente vulnerável às transformações na divisão territorial do trabalho hegemônica.

No circuito superior estão os agentes hegemônicos usuários e produtores das variáveis modernas do período, enquanto o inferior compõese de uma multiplicidade de atividades pouco capitalizadas que imprescindem do uso de técnicas contemporâneas - embora novos objetos sejam utilizados em menor grau e frequentemente a partir de outras combinações - e aumenta pela produção de pobreza e dívidas sociais, resultado direto das modernizações tecnológicas e organizacionais contemporâneas que têm fortalecido o circuito superior das economias urbanas (SILVEIRA, 2011).

A pesquisa desenvolvida ainda indica que as empresas de transporte rodoviário de carga pensam o Brasil no sentido longitudinal (norte-sul), até uma faixa de cerca de $200 \mathrm{~km}$ do litoral no Nordeste e de 600 km na Região Concentrada - obviamente onde se concentram os seus principais centros produtores e consumidores. Fora dessa zona, apenas alguns nodais e relês aparecem como centralidades associadas ao TRC no Brasil contemporâneo, fato que de certa forma demonstra a leitura territorial de "estilo christalliana" exercida pelo mercado, entendida como uma construção idealizada do espaço regional cujo princípio de mercado é a grande força estruturadora. Esta ótica não privilegia a produção de bens, mas a oferta de bens e prestação de serviços vinculadas a lugares centrais - que nesta pesquisa se confundem com os nodais do TRC.

Isso também significa que, de forma geral, o atendimento ao extenso interior do país é feito de modo mais otimizado e lento, pois o crescimento das distâncias é proporcional à diminuição dos mercados (ou seja, menos carga para transportar), situação que requer do transportador ajustes, adaptações e parcerias. A pesquisa também demonstra que a distribuição espacial de nodais ao longo do território nacional pode ser um dos indicadores das crônicas e históricas desigualdades regionais, principal característica da formação socioespacial brasileira.

\section{UBERLÂNDIA: EPICENTRO LOGÍSTICO DO SETOR ATACADISTA-DISTRIBUIDOR}

A emergência da centralidade de Uberlândia no cenário nacional como polo atacadista e distribuidor remonta ao século XVIII, quando o então chamado "sertão da farinha podre" tornou-se ponto estratégico na rota São Paulo-Goiás, adquirindo gradativamente um papel histórico de abastecimento. Com a chegada da ferrovia, em 1888, Uberlândia se transforma na "boca do sertão", um entroncamento de produtos agropecuários que se insere no circuito mercantil do país e possibilita a ocupação econômica da região, promovendo "o desenvolvimento de um setor que toma a frente no processo de acumulação do capital até a atualidade: o comércio" (CLEPS, 2000, p.9).

Mas é o modal rodoviário que de fato expande as possibilidades pretéritas. A construção de uma estrada de rodagem até o Rio Paranaíba (Figura 1), obra custeada com capitais locais pela Companhia Mineira de Auto-Viação Intermunicipal, e da ponte sobre o referido rio, em Itumbiara (GO), além da instalação de serviços de telefonia, energia elétrica, abastecimento de água e bancários, auxiliam na consolidação de Uberlândia como entreposto comercial que garante o escoamento rápido e contínuo de produtos agropecuários de Mato Grosso, Goiás e Triângulo Mineiro. 
Figura 1. Motoristas em manifestação na Ponte do Vau contra cobrança de pedágio pela Cia. Mineira de Auto-Viação (1948).

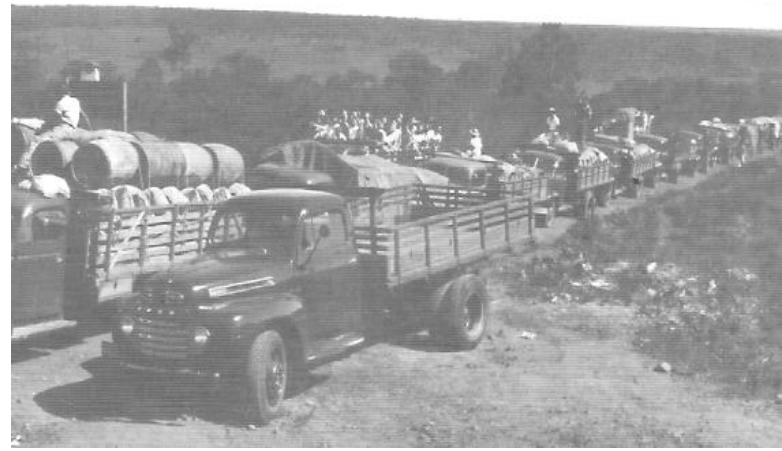

Fonte: Acervo João Quituba - CDHIS/UFU

Além disso, é implantado um sistema muito particular de comercialização, que tem na figura do motorista (chauffeur) a engrenagem principal: “... depois de percorrerem de forma autônoma e com veículos próprios as cidades da região recolhendo os pedidos de compra dos varejistas, retornavam a Uberlândia e saíam a procura dos produtos que lhes tinham sido encomendados" (CLEPS, 2000, p.11). Os motoristas viajavam em grupos e carregavam apetrechos necessários em casos de atolagem, como cabos de aço, correntes e macacos.

Com a construção de Brasília, na década de 1950, há um novo ciclo de interiorização da infraestrutura, e "as velhas estradas de 'chão' cederam lugar ao asfalto, impulsionando as atividades comerciais de Uberlândia que, no contexto da divisão territorial do trabalho, era favorecida pela sua posição de entroncamento para o escoamento da produção do Centro-Oeste e fornecedora de produtos pecuários e de cereais ao Sudeste" (CLEPS, 2000, p.11). De fato, a cidade do Triângulo Mineiro é beneficiada pela implantação de um rosário de estradas federais em todas as direções que lhe garante uma condição territorial bastante particular (Figura 2), tendo a BR050 (divisa SP/MG a Cristalina/GO) como principal corredor (Figura 3).

Figura 2. Configuração territorial do ponto nodal de Uberlândia

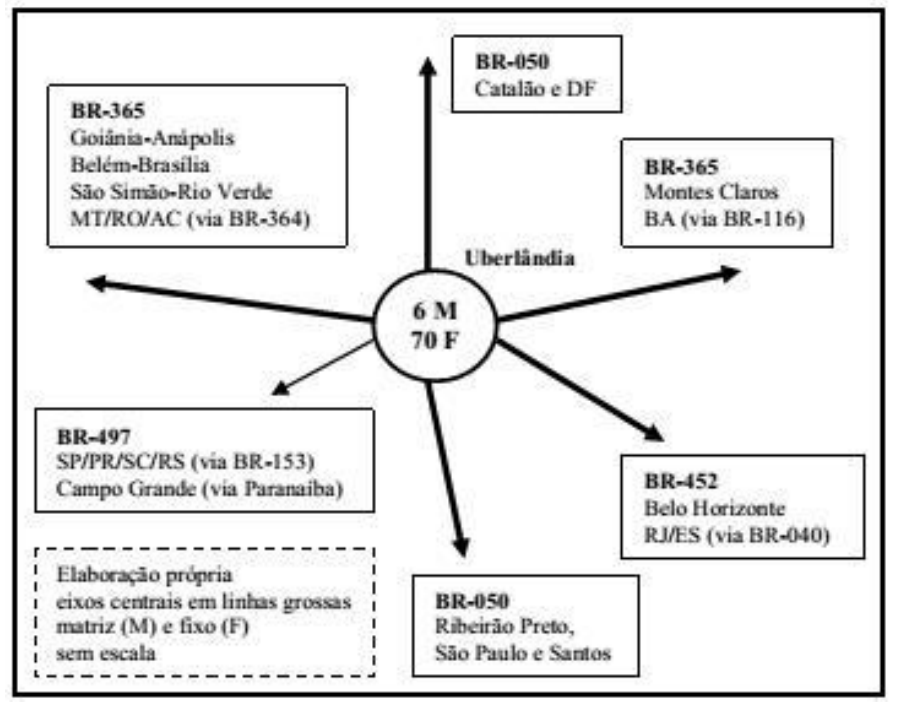

Organização do autor. 
Figura 3. BR-050 nas proximidades de Uberlândia

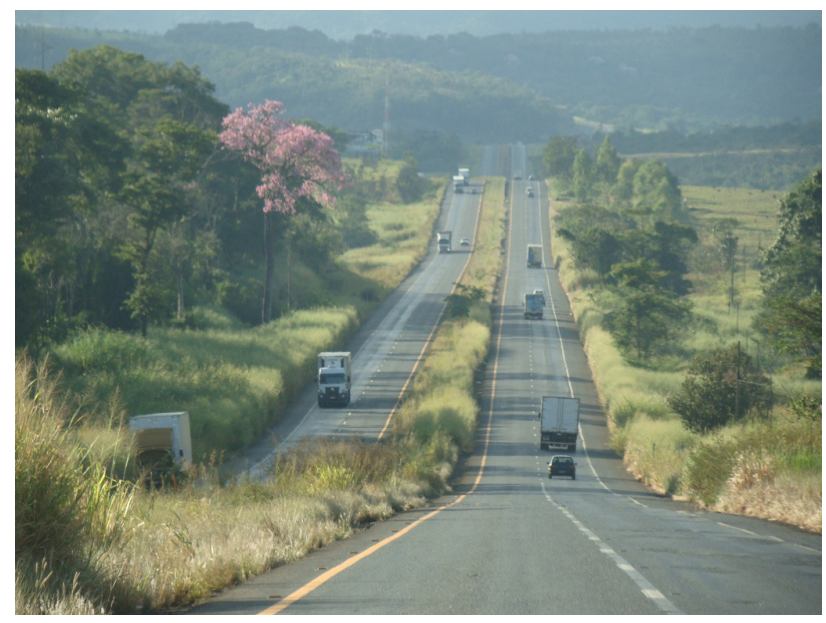

Fonte: Foto de Selma Marsson (07.mai.2010)

O comércio atacadista que havia crescido nas duas décadas anteriores - principalmente de peças de automóveis, tecidos, armarinhos, ferramentas, material de construção, derivados de petróleo e medicamentos - em uma relação de extrema confiança com o motorista passa a se especializar, além de instituir outras formas de pagamento com prazos variados e de constituir a sua frota própria, diminuindo a relação com os motoristas.

É nesse período, de forte emergência do meio técnico-científico-informacional, que se consolidam as cinco grandes empresas atacadistas-distribuidoras atuais - Arcom, Martins, Aliança, União e Peixoto. “Aliando a posição geográfica estratégica construída ao longo do tempo, a agressiva postura empresarial na conquista dos mercados emergentes brasileiros à constante busca de tecnologia em distribuição, logística, informática, gestão empresarial, marketing e know-how, os atacadistas de Uberlândia acabaram gerando um elevado nível de eficiência que os tornou altamente competitivos, mesmo nas regiões produtoras dos bens por eles distribuídos, como é o caso da própria metrópole paulista" (CLEPS, 2000, p.15, grifos do original).

Cabe ressaltar que o atacado possui diferentes formatos de atuação, que segundo a Associação Brasileira de Atacadistas e Distribuidores de Produtos Industrializados (Abad) são classificados de acordo com o modelo principal de atendimento aos clientes. $\mathrm{O}$ atacadista é um "agente de distribuição que compra e vende produtos de fornecedores da indústria, com os quais não possui vínculo (formal ou informal) de exclusividade de produtos e/ou de território". Já o distribuidor é um "agente de distribuição que compra e vende produtos de fornecedores da indústria, com os quais possui vínculo de exclusividade de produtos e/ou de território", segundo a Abad.

Portanto, trata-se de empresas comerciais com foco no abastecimento de pequenos pontos de venda e que têm na logística um fator fundamental. "Existe complementariedade com o transportador, pois nem todos transportam por si", comentou Daniel Pascalicchio, assessor comercial da Abad (entrevista concedida por telefone em 07.abr.2011), explicando que a frota própria é mais utilizada na microescala (fluxos T2), com imprescindível planejamento de rotas e gestão de frota.

A Abad reitera o fato de que no mercado brasileiro há diversas empresas que atuam como atacadistas para um determinado grupo de fornecedores ao mesmo tempo em que atuam como distribuidores para um outro grupo de fornecedores, e devem ser caracterizadas como empresas atacadistas e distribuidoras, caso específico das firmas do ponto nodal de Uberlândia. Os demais formatos são atacado de autosserviço, atacado de balcão e atacado operador.

Em seu trabalho sobre o papel intermediário dos atacadistas no período atual, Marcos Xavier nos explica que a capacidade de reposição fracionada de pequenos volumes de mercadorias em milhares 
de pontos de varejo no território nacional permite a sobrevivência e a posição estratégica do setor na relação entre indústria e varejo, cuja pertinência se dá pela "dificuldade das indústrias atenderem o pequeno varejo por este formar uma verdadeira constelação de lojas de vizinhança espalhadas por milhares de centros urbanos em todo o território e pelos bairros das grandes cidades" (XAVIER, 2009, p.91).

As indústrias, com a finalidade de ampliar o contexto de sua distribuição, encontram nos atacadistas um meio de atingir um cliente que exige um sistema de distribuição de produtos diversificados, fracionados em pequenos volumes e que demanda reposições de estoque frequentes, o que tornam complexas $e$ onerosas as operações de entrega (XAVIER, 2009, p.91).

As novas qualidades e quantidades do consumo associadas ao tamanho do território, à diversidade de hábitos, valores e costumes e à distribuição desigual das modernizações e da população desafiam as empresas a adotarem novas estratégias de marketing e logística de distribuição para atingir e atender adequadamente os inúmeros pontos de venda distribuídos de forma capilar no território nacional (XAVIER, 2009, p.84).

Em relação ao TRC e ao ponto nodal de Uberlândia interessa compreender de que forma se dão as correlações entre empresas transportadoras e empresas atacadistas-distribuidoras, já que estas operam carga própria e a princípio, pelo exposto na lei $\mathrm{n}^{\mathrm{o}} 11.442 / 07$, não podem realizar o serviço de transporte para terceiros. Partindo-se do pressuposto de que a capilaridade territorial proporcionada por este segmento tem origem em seus grandes fixos de distribuição situados em Uberlândia, o nexo territorial evidencia-se no papel no qual as ETCs assumem para supri-los, coletando as mercadorias em fluxos $\mathrm{T} 1$ aonde elas são fabricadas.

Localizamos na cidade 70 fixos de ETCs com matriz em 13 Estados (SP/26, MG/10, GO/9, PR/6, $\mathrm{RS} / 3, \mathrm{SC} / 3, \mathrm{ES} / 3, \mathrm{RJ} / 3, \mathrm{MT} / 2, \mathrm{AM} / 2, \mathrm{MS} / 1, \mathrm{PE} / 1 \mathrm{e}$ $\mathrm{AC} / 1)$, o que de certa forma pode reafirmar essa condi- ção. Das ETCs locais, a Unilog afirma em seu sítio que um de seus segmentos é a armazenagem, paletização e entrega para os principais atacadistas da cidade. A empresa possui 11 filiais em todas as regiões do país (Maribuba/PA, Fortaleza, Campina Grande, Jaboatão dos Guararapes/PE, Simões Filho/BA, Itabuna/BA, Aparecida de Goiânia, Montes Claros/MG, Cordeirópolis/SP, Osasco e Joinville/SC).

Como constatou Xavier (2009), a logística de distribuição é um dos desafios para o setor atacadista e varejista diante da proliferação territorial do consumo popular de produtos de mercearia básica, e podemos afirmar que os atacadistas-distribuidores contratam o serviço de transporte em algum ponto de sua escala de atuação, tornando-se assim embarcadores. Estudos posteriores poderiam avaliar com mais precisão em quais etapas isso ocorre, mas na pesquisa de campo constatamos que ETCs regionais como a Expresso Grão-Pará e a Marajó Transportes, da Paraíba, têm entre seus clientes atacadistas-distribuidores para fluxos T2.

Dentre as cinco empresas atacadistas-distribuidoras citadas anteriormente, a Martins é a maior do país, com faturamento de $\mathrm{R} \$ 3,4$ bilhões em 2011. Na década de 1960, quando o empresário Alair Martins do Nascimento trocou o comércio varejista pelo atacado, alegava que "num país do tamanho do Brasil, nenhuma indústria seria capaz de levar seus produtos para todos os pontos de vendas que se iam abrindo no interior" (CLEPS, 2000, p.28). A empresa conta com frota própria de 1.100 veículos e mais 190 terceirizados para movimentação de 17 mil itens comercializados (alimentos, bebidas, bazar, limpeza, higiene, beleza, material de construção, agroveterinário, eletroeletrônicos e informática) com cerca de 376 mil clientes ativos em todos os municípios brasileiros.

Seus fluxos ocorrem a partir da Central de Distribuição (CD) de Uberlândia, com capacidade para armazenar cerca de 2,7 milhões $\mathrm{m}^{3}$ e 126 mil pallets, para as Unidades Regionais de Negócio (URNs) de Manaus, Ananindeua, Jaboatão e Camaçari - de onde provavelmente partem fluxos T1/B, T1/C e T2 para as regiões Norte e Nordeste - e para as demais filiais de cross-docking que originam fluxos T2 para as demais zonas do país. Também chamados de Centros de Distribuição Avançada (CDA), estão situados em 
Porto Velho, Santarém, Araguaína e Palmas (Norte); São Luís, Imperatriz, Teresina, Fortaleza, Crato/CE, Natal, Maceió, Aracaju, Barreiras/BA e Vitória da Conquista/BA (Nordeste); Sinop/MT, Cuiabá, Campo Grande, Ceres/GO, Brasília e Rio Verde/GO (Centro-Oeste); Montes Claros, Governador Valadares, Belo Horizonte, Juiz de Fora, Pouso Alegre/MG, Vitória, Rio de Janeiro, São Paulo, Marília, Ribeirão Preto e São José do Rio Preto (Sudeste) e Santa Maria/RS, Passo Fundo/RS, Porto Alegre, Itajaí, Tubarão/SC, Curitiba, Cascavel e Londrina (Sul).

Em 1989 a Martins criou a Marbo Transportadora, cujo objetivo principal era coletar mercadorias nas indústrias e transportá-las até Uberlândia para posterior distribuição. A Marbo contou com 600 carretas e 482 cavalos mecânicos distribuídos em 12 filiais, percorrendo mais de 10 milhões de quilômetros por mês - o equivalente a 200 voltas completas em torno do planeta ou a 17 viagens à Lua (CLEPS, 2000).

Sete anos depois, Martins e Marbo envolvem-se em uma reorganização societária reversa na qual a controladora (Martins) é adquirida pela controlada (Marbo), que posteriormente retoma a razão social da antiga controladora. Sucessivos prejuízos fiscais acumulados pela transportadora foram a razão da engenharia empresarial, contestada e autuada pela Receita Federal, mas o Acórdão CSRF/01-05.414, que tratou da análise do caso na Câmara Superior de Recursos Fiscais, embasou a conclusão de que a incorporação reversa da Martins pela Marbo foi encadeada por legítimos desígnios de reorganização societária (JUNIOR e SOUZA, 2010). De qualquer forma, a Marbo deixou de existir.

A empresa Arcom detém estrutura com frota própria de 1 mil veículos, uma $\mathrm{CD}$ em Uberlândia com capacidade para $620 \mathrm{mil} \mathrm{m}^{3}$ e CDAs em São Paulo e Rio de Janeiro para entregas a 150 mil clientes ativos das regiões Sul, Sudeste e Centro-Oeste, Bahia, Sergipe, Alagoas e Tocantins. O seu sistema de roteirização forma as cargas e calcula as melhores rotas a ser percorridas, que dependendo do volume comercializado podem ser por Estado, microrregião e munícipio (respectivamente fluxos T1, T2/D e T2/E e T2/F).

A empresa Peixoto conta com 350 veículos para atendimento de 90 mil clientes em 4 mil mu- nicípios, totalizando cerca de 80 mil entregas por mês. A sua estrutura logística é composta pela $\mathrm{CD}$ de Uberlândia, com capacidade para $280 \mathrm{mil} \mathrm{m}^{3}$; CDA de São Paulo e Centros de Distribuição Econômicos (CDEs) de Porto Velho, Araguaína e Belém (Norte); Santa Inês/MA, Feira de Santana, Vitória da Conquista e Ibotirama/BA (Nordeste); Brasília (Centro-Oeste); Montes Claros, Governador Valadares, Ubá/MG, Belo Horizonte, Três Corações/MG, Rio de Janeiro, São José do Rio Preto, Marília, Ribeirão Preto, Limeira/SP e Itapetininga/SP (Sudeste) e Porto Alegre, Cascavel, Curitiba e Londrina (Sul). Como estratégia de controle da equipe de vendas, a empresa adota uma regionalização por zonas, e não por localidades, diferentemente dos demais atacadistas-distribuidores (Cleps, 2000).

A empresa União, cuja CD de Uberlândia conta com $10.700 \mathrm{~m}^{2}$ de área, possui cerca de $60 \mathrm{mil}$ clientes nas regiões Sudeste e Centro-Oeste; Bahia, Sergipe, Alagoas, Ceará, Piauí e Maranhão; e Tocantins, Pará e Amapá, atendidos por frota própria de 100 veículos e 161 terceirizados. A empresa não conta com outros fixos e o atendimento ao cliente depende da distância e data do pedido, e pode levar até 10 dias mas num raio de $400 \mathrm{~km}$ de Uberlândia o prazo é de no máximo dois dias (CLEPS, 2000).

Fora do âmbito atacadista-distribuidor, constatamos ainda cinco ETCs locais: Cocal, que opera granel sólido agrícola; TC Logística, de carga geral e filiais no Rio Grande do Sul, Nordeste, Manaus e Ananindeua; TBR, de carga geral e granel sólido e insumos agrícolas, com filiais em Alto Araguaia (MT), Paulínia, Rio Verde (GO) e Curitiba; RodoExtra, de carga geral e filial em Osasco; e Caiapó, de carga geral e filiais em Uberaba, Araguari (MG), São Paulo e Goiânia. Esta empresa surgiu em 2002 de um projeto de um grupo de alunos da Universidade Federal de Uberlândia (UFU).

É preciso mencionar que a Supporte Logística Integrada detém a concessão do Entreposto da Zona Franca de Manaus (ETZM) em funcionamento na cidade desde 2010, com estrutura para armazenagem de $50 \mathrm{mil} \mathrm{m}^{2}$, e que funciona nos moldes de postergação tributária do similar de Resende (RJ). A empresa deixou de operar o transporte com frota própria e com autônomos agregados, contratando o serviço de outras ETCs para o cliente, modelo que chama de 
"integrador logístico".

Da capital amazonense para Uberlândia (fluxo T1/A com caminhão lacrado), a Supporte trabalha com grandes ETCs - Quick, Transpacífico, Gab, Atlas, SCR, SR, Coopercarga, Schio etc - e da cidade mineira para o restante do país, em fluxos T1 e T2, subcontrata autônomos independentes (40\%) e ETCs de todos os portes $(60 \%)$, de acordo com Fábio Carvalho, coordenador de transportes da empresa (entrevista realizada em Uberlândia em 07.nov.2011). Em 2011 a Supporte foi questionada pela Sefaz/AM e Suframa o porquê da operação abaixo da capacidade e das expectativas, pois naquela ocasião apenas 18 fabricantes instalados no Polo Industrial de Manaus (PIM) utilizavam os serviços do entreposto. "A Suframa não entende que não depende só da gente e o fato de ser entreposto não garante o cliente, pois demandas desse tipo envolvem parte comercial e projetos e precisam do aval das matrizes dos fabricantes", argumentou Carvalho.

Uberlândia ainda possui uma unidade do Sest/ Senat, um terminal de carregamento de combustível e um Clia com estrutura ferroviária aos portos de Santos, Vitória e Rio de Janeiro. A cidade também se destaca no transporte dos circuitos produtivos do agronegócio.

\section{CONSIDERAÇÕES FINAIS}

$\mathrm{O}$ artigo procurou demonstrar que a análise contemporânea da formação socioespacial brasileira pode ser realizada a partir de uma rede geográfica caracterizada pela ocorrência de centralidades relacionadas diretamente com o transporte rodoviário de carga. Os nodais, tidos como máxima expressão da seletividade espacial, são constituídos por atributos geográficos que reforçam o seu papel de comando na operação, normatização e operacionalização das atividades correlatas ao transporte rodoviário de carga.

Na topologia proposta, a cidade de Uberlândia aparece como um nodal secundário monofuncional por causa de sua histórica relação com o setor atacador-distribuidor, corroborando o seu papel de epicentro logístico desta atividade. Mas para que isso fosse possível, revelou-se a imprescindível e intensa participação dos agentes do transporte rodoviário de carga. Apesar de possuir frota própria, as maiores empresas da atividade em questão (Martins, Arcom, Peixoto,
Aliança e União) necessitam recorrer ao artifício da contratação do frete de terceiros para atingir todo o território nacional, movimento que por sua vez leva a outras subcontratações nas mais diferentes escalas geográficas. O território evidencia estas relações, além de uma vez mais comprovar que a situação geográfica da principal cidade do Triângulo Mineiro, entre São Paulo, Belo Horizonte, Brasília e Goiânia, é um fator que precisa ser levado em consideração em análises relativas à circulação.

\section{REFERENCIAS}

ARROYO, Mónica. Dinâmica territorial, circulação e cidades médias. In: SPOSITO, Eliseu Savério; SPOSITO, Maria Encarnação Beltrão; SOBARZO, Oscar (orgs.). Cidades médias: produção do espaço urbano e regional. São Paulo: Expressão Popular, 2006, p.71-85.

ARROYO, Mónica. La división territorial del trabajo: un proceso e una categoría para intepretar el mundo. In: $4^{\text {a }}$ CONFERÊNCIA INTERNACIONAL DE GEOGRAFIA CRÍTICA. Ciudad de México, 2005. Anais..., Ciudad de México, 2005, p.1-12.

BRAGA, Vanderlei. Logística e uso do território brasileiro: tipologia e topologia de nós logísticos e o projeto da Plataforma Multimodal de Goiás (PLMG). 2013. Tese (Doutorado em Geografia), Universidade de Campinas, Campinas, 2013.

BRANDÃO, Antônio Carlos. Território e desenvolvimento: as múltiplas escalas entre o local e o global. Campinas: Unicamp, 2009.

CLEPS, Geisa Daise Gumiero. A origem e o desenvolvimento do comércio atacadista de Uberlândia (MG). Sociedade \& Natureza. Uberlândia, ano 12, n.1, p.5-45. 2000

CASTILLO, Ricardo Abid. Agricultura globalizada e logística nos cerrados brasileiros. In: SILVEIRA, Márcio Rogério (org.). Circulação, transportes e logística. São Paulo: Outras Expressões, 2011, p.331-54. 
CLOZIER, Réne. Géographie de la circulation. Paris: Génin, 1963.

CORRÊA, Roberto Lobato. Estudos sobre a rede urbana. Rio de Janeiro: Bertrand Brasil, 2006.

CORREAA, Roberto Lobato. Interações espaciais. In: CASTRO, Iná Elias de; GOMES, Paulo César da Costa e CORREAA, Roberto Lobato (org.). Explorações geográficas: percursos no fim do século. Rio de Janeiro: Bertrand Brasil, 1997, p.279-318.

GIÚDICE, Fernando. Como gerir a variação sazonal da demanda. Anuário NTC\&Logística 2011/2012. São Paulo, 2012, p.134-37.

HUERTAS, Daniel Monteiro. Território e circulação: transporte rodoviário de carga no Brasil. 2013. Tese (Doutorado em Geografia), FFLCH/USP, São Paulo, 2013.

JUNIOR, Valdenicio Rafael Vieira e SOUZA, Vagner Luz Agareno de. Ética no desenvolvimento das operações de reorganização societária, Disponível em: <www.ccsa.ufrn.br/seminario2010/anais/artigos/ gt10-10.pdf $>$, acesso em: 30.out.2012.

MARX, Karl. O capital: crítica da economia política - Livro Segundo: O processo de circulação do capital, volume III. 13.ed. Rio de Janeiro: Civilização Brasileira, 2011 [1893].

RAFFESTIN, Claude. Por uma geografia do poder. São Paulo: Ática, 1993 [1980].

SANTOS, Milton. O espaço dividido: os dois circuitos da economia urbana dos países subdesenvolvidos. $2^{\mathrm{a}}$ ed. São Paulo: Edusp, 2008 [1979].

SANTOS, Milton. A urbanização brasileira. 5.ed. São Paulo: Edusp, 2005 [1993].

SANTOS, Milton. A natureza do espaço. Técnica e tempo. Razão e emoção. 4.ed. São Paulo: Edusp, 2004 [1996].
SANTOS, Milton. Economia espacial: críticas e alternativas. 2.ed. São Paulo: Edusp, 2003 [1979].

SANTOS, Milton. Metamorfoses do espaço habitado. São Paulo: Hucitec, 1988.

SAVY, Michel. Logistique et territoire. Espace géographique. Tome 22, nº 3, p.210-18, 1993.

SILVA JUNIOR, Roberto França. Geografia de redes e da logística no transporte rodoviário de cargas: fluxos e mobilidade geográfica do capital. 2004. Dissertação (Mestrado em Geografia), Universidade Estadual Paulista, Presidente Prudente, 2004.

SILVEIRA, María Laura. Modernizações territoriais e circuitos da economia urbana no Brasil. In: XVI ENCONTRO NACIONAL DAANPUR, Rio de Janeiro, 2011. Anais... Rio de Janeiro, 2011, p.1-21.

THOMSON, J. M. Teoría económica del transporte. Madrid: Alianza Editorial, 1976.

XAVIER, Marcos Antonio de Moraes. Os elos entre os circuitos da economia urbana brasileira no atual periodo: os atacadistas e seu papel intermediário. Tese (Doutorado em Geografia), Universidade Estadual de Campinas, Campinas, 2009.

Soc. \& Nat., Uberlândia, 26 (3): 445-458, set/dez/2014 